\title{
Intercambio académico y disputas internacionales: La Universidad de Buenos Aires en los años 20
}

\author{
[Academic Exchange and International Disputes: \\ The University of Buenos Aires in the $20 \mathrm{~s}$ ]
}

\author{
Pablo Buchbinder \\ (Universidad de Buenos Aires/ \\ Consejo Nacional de Investigaciones Científicas y Técnicas, Argentina) \\ pbuchbin@retina.ar
}

\section{Resumen}

El objetivo del artículo consiste en analizar el intercambio académico en la Universidad de Buenos Aires (UBA) durante la década de 1920. El texto focaliza en las disputas entre diferentes grupos relacionados con distintas comunidades nacionales que intentaron monopolizar los vínculos académicos con la UBA. Se estudia el papel de instituciones intermediarias y las diferentes estrategias de los distintos grupos académicos y diplomáticos para fortalecer su presencia en el ámbito universitario argentino. También se analiza el impacto del intercambio sobre la vida cultural de la ciudad de Buenos Aires y sobre las actividades de enseñanza e investigación de la Universidad.

Palabras claves: Universidad - Ciencia Diplomacia - Profesionalismo.

\begin{abstract}
The objective of this article is to analyze the academic exchange at the University of Buenos Aires (UBA) during the 1920s. The text focuses on disputes between different groups related to different national communities that tried to monopolize academic links with the UBA. Both the impact of academic exchange on the cultural life of the city of Buenos Aires and the activities of teaching and research at the University are analyzed.
\end{abstract}

Keywords: University $\quad-\quad$ Science -
Diplomacy - Professionalism.

Recibido: 12/02/2019

Evaluación: 09/05/2019

Aceptado: 14/06/2019

Anuario de la Escuela de Historia Virtual - Año 10 - No 16 - 2019: pp. 25-50.

ISSN: 1853-7049

http://revistas.unc.edu.ar/index.php/anuariohistoria 


\section{Intercambio académico y disputas internacionales: La Universidad de Buenos Aires en los años 20}

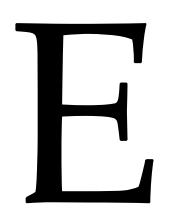

1 propósito de este texto consiste en analizar diversos aspectos de las prácticas de intercambio académico en el Buenos Aires de los años 20. En este sentido, el artículo forma parte de un proyecto mayor dedicado a estudiar las dimensiones políticas e intelectuales del intercambio en el ámbito de la UBA desde la primera década del siglo XX hasta el inicio de la Segunda Guerra Mundial. Problemas de esta naturaleza han sido explorados durante los últimos años. Diversos investigadores han indagado en la confrontación de prácticas universitarias y de modos de comprender el trabajo académico y científico en diferentes estados (Charle, Schriewer, y Wagner, 2006; Salvatore, 2004).

Nuestro objetivo, en cambio, consiste en analizar el intercambio en el contexto de la historia de la UBA. Creemos que estas experiencias no han sido indagadas prestando atención prioritaria a las relaciones habituales de competencia y rivalidad que las signaron como tampoco al impacto e interacción con los actores locales.

En este marco nos parece importante subrayar que la historia del intercambio científico o de las migraciones académicas que tuvieron su escenario en el ámbito de la UBA no se inició en los años veinte. Constituye parte de un proceso que recorre la historia de esta institución desde sus orígenes. La llegada a la Argentina de científicos y académicos europeos se originó, por lo general, en vínculos personales establecidos entre quienes fueron contratados y agentes de la burocracia o el gobierno. A principios del siglo XX se intentó reemplazar, aunque parcialmente, estos procedimientos o prácticas por otros que procuraron priorizar los vínculos formales entre dependencias estatales $\mathrm{y}$, sobre todo, entre las Universidades.

Estos intentos se efectivizaron en un contexto en el que el intercambio académico cobró relevancia como un instrumento de la política cultural de los estados europeos. Tempranamente la difusión del idioma y el apoyo a las escuelas particulares constituyó un eje fundamental de la diplomacia europea. Actos como la fundación de la Alianza Francesa en 1883 y de la Sociedad Dante Alighieri en 1889 tuvieron un papel central en estos procesos. El rol de las misiones científicas francesas en el exterior fue especialmente significativo en este contexto. El proceso de expansión imperialista impulsado desde mediados del siglo XIX incluyó, obviamente, dimensiones científicas y culturales. El traslado de científicos, técnicos y académicos desde los principales estados europeos hacia la periferia y las colonias constituyó uno de los rasgos singulares de la época del imperialismo. Las instituciones culturales creadas durante estos años fueron, como ha señalado Pyenson (1985), vehículos centrales de esta política. Pero debe recordarse también, en este sentido, que no todos los estados que protagonizaron estos procesos le 
otorgaron a las políticas científicas y culturales la misma relevancia. En el caso francés, estas estrategias aparecieron tempranamente y pueden datarse incluso en períodos anteriores a la conformación del sistema de colonias. La Escuela Francesa de arqueología en Atenas en 1846, la Escuela Francesa de Roma en 1875 o la casa de Velázquez en Madrid más tardíamente, en 1928, expresaron este rasgo de la política imperial francesa que también contó, aunque algo más tarde, con un importante capítulo latinoamericano. En 1923 se creó el Instituto de Alta Cultura Franco-Brasileño, en 1927 el Instituto Peruano de Alta Cultura y, en 1930, el Instituto de Alta Cultura de Bogotá.

Los alemanes, en cambio, iniciaron sus aventuras coloniales más tardíamente, ya que, luego de la constitución del estado nacional en 1871, el foco principal de su política exterior estuvo centrado en la afirmación de su papel en el continente. En sus inicios, entonces, la política de expansión en términos científicos y educativos encontró su campo principal en la misma Europa. Los intentos de germanizar la Universidad de Estrasburgo, capital de Alsacia constituyen un ejemplo en ese sentido. A principios del siglo XX tomaron forma más sustantiva los esfuerzos por extender los modelos académicos y científicos germanos más allá del continente. A diferencia de los franceses, que privilegiaron diversas disciplinas y que otorgaron un papel clave a las humanidades, en el caso alemán, las ciencias exactas y naturales ocuparon un papel central (Pyenson, 1985).

Sin embargo, luego de la Primera Guerra Mundial la inquietud por fortalecer la faz cultural de la política exterior cobró particular intensidad. En este contexto, fueron creados en los Servicios Diplomáticos secciones ocupadas especialmente de las dimensiones culturales. El renovado lugar que ocupó en los primeros años de la posguerra la política cultural debe comprenderse a partir de un balance en torno a las debilidades de la política exterior tradicional. Si bien la idea de que la influencia económica tenía un efecto limitado en este campo ya era común a finales del siglo XIX, fue entonces cuando la política cultural apareció como una instancia decisiva a la hora de generar instrumentos para ganar a la opinión pública de terceros países. Pero también, y paralelamente, la intensificación de los vínculos culturales fue percibida como uno de los mecanismos para estimular una atmósfera de mayor cordialidad y comprensión entre las naciones. Trabajos recientes han subrayado la tensión entre los esfuerzos realizados desde el siglo XVIII por definir a las ciencias como auténticamente internacionales, "como proyectos intelectuales globales" (Wagner, 2006, pp. 13-21) y el crecimiento de controversias en las que los aspectos científicos fueron cruzados por consideraciones nacionalistas. En esta perspectiva se ha insistido en la forma en que surgieron problemas, vocabularios, técnicas, categorías y procedimientos comunes a prácticas científicas desarrolladas en distintos espacios nacionales. Al mismo tiempo, se ha destacado que este proceso de globalización fue afectado por el auge del nacionalismo desde finales del siglo XIX y, sobre todo, por el impacto de la Primera Guerra Mundial que fragmentó a la comunidad científica internacional. En los años veinte hubo diversos intentos para limitar estos efectos y tender puentes entre los investigadores de los distintos Anuario de la Escuela de Historia Virtual - Año 10 - ํo 16 - 2019: pp. 25-50. ISSN: 1853-7049 
países. La creación, a mediados de la década de 1920, de la Oficina de Cooperación Intelectual dependiente de la Sociedad de las Naciones puede comprenderse en este marco. Sin embargo, estos esfuerzos no lograron socavar las tensiones que continuaron reproduciéndose en ámbitos científicos y universitarios durante el período de entreguerras.

En este nuevo marco tuvo también lugar, en el caso galo, la creación del Service des Oeuvres Françaises à l'Étranger, constituido en 1920 -que reemplazó al Bureau des Écoles et des Oeuvres Françaises à l'Étranger, fundado en 1900- y que tenía el propósito de estimular el intercambio de profesores universitarios, conceder becas a estudiantes extranjeros y supervisar la fundación y las actividades de escuelas y liceos franceses en el exterior. Los alemanes respondieron con la creación de una serie de oficinas orientadas con el mismo propósito y que culminaron con el surgimiento del Servicio Alemán de Intercambio Académico (DAAD) en 1925 (De la Hera Martínez, 2003; Delgado Gómez Escalonilla, 1992). Sin embargo, una característica que diferenció en este aspecto a la política alemana de la francesa -fuertemente centralizada- fue la conformación de iniciativas con el mismo objetivo por parte de las universidades o, incluso, de instituciones particulares como la Fundación Alexander von Humboldt en 1927 con una limitada coordinación.

\section{La organización sistemática del intercambio académico: los primeros ensayos}

Los primeros ecos de la competencia entre alemanes y franceses por monopolizar los vínculos culturales y universitarios con terceros países llegaron a la Argentina en los primeros años del siglo XX. Puede advertirse así, particularmente en los casos de los académicos de Ciencias Médicas y Ciencias Exactas, una voluntad muy clara de articular a sus facultades en el movimiento científico internacional sobre la base de la idea de que el aporte extranjero, sobre todo europeo, cumpliría un papel fundamental en la transformación de la UBA en una dirección más científica y menos profesionalista. ${ }^{1}$

Las propuestas para fomentar el intercambio académico se aceleraron en tiempos del centenario. Fue particularmente importante, en este sentido, la visita del español Rafael Altamira en 1909, la de su compatriota Adolfo González Posada un año después, y la del historiador de la literatura y figura central de las instituciones francesas orientadas al intercambio académico, Ernest Martinenche, ese mismo año.

Pero, para el tema que nos ocupa, la cuestión más importante reside en las iniciativas para articular un intercambio de profesores de manera permanente. El Instituto Carnegie para la Paz Internacional procuró, en 1912, interesar a la UBA en el fomento del intercambio de estudiantes y profesores entre universidades norteamericanas y

\footnotetext{
${ }^{1}$ Con el término profesionalismo se denota la concentración casi exclusiva de la actividad universitaria en la formación de profesionales liberales.
}

Anuario de la Escuela de Historia Virtual - Año 10 - Nº 16 - 2019: pp. 25-50. ISSN: 1853-7049 
argentinas sin despertar demasiado interés (Salvatore, 2004a). ${ }^{2}$ Las dos iniciativas que, en cambio, provocaron el debate de los universitarios porteños fueron las de Francia y Alemania. Las negociaciones se iniciaron a partir de contactos informales establecidos por tres destacados académicos y juristas argentinos. Antonio Dellepiane y Horacio Piñero fueron fundamentales para el intercambio con Francia y Ernesto Quesada para Alemania. En agosto de 1913 se aprobó una ordenanza sobre intercambio de profesores con universidades francesas. ${ }^{3}$ El acuerdo se llevaba a cabo con la Inspección Superior de Francia y procuraba implementar un intercambio permanente. La principal ventaja era, según lo señalado por los académicos argentinos, que la UBA se adjudicaba la potestad de indicar cada año a la Inspección la nómina de los profesores que dictarían conferencias y cursos en las facultades. El hecho de que se delegase en la UBA la elección de los profesores franceses era percibido positivamente por los académicos argentinos, ya que lo entendían como un reconocimiento del prestigio académico de la institución.

El modelo alemán que gestionó Ernesto Quesada, por los mismos años, era distinto. Según informó al Consejo Superior, la Universidad de Berlín proponía para la UBA un intercambio similar al que desarrollaba con Harvard y Columbia. La Universidad alemana podría enviar regularmente profesores a dar clase en español a Buenos Aires, pero, para garantizar el éxito del intercambio y, en consecuencia, que este pudiese continuar durante varios años, era preciso que la UBA lograse presentar 12 candidatos para dar clase sobre su disciplina en Alemania en alemán. ${ }^{4}$ Por esta razón, la iniciativa tuvo escaso éxito.

Puede advertirse así cómo los modelos que se proponían desde ambos países presentaban diferencias significativas. Las controversias se desarrollaron entonces sobre la base de argumentos académicos que, en principio, no estuvieron impregnados de consideraciones políticas. Ernesto Quesada señaló que la idea moderna del intercambio consistía en que una disciplina determinada fuese enseñada en Alemania con criterio americano durante un período de al menos un semestre y que, la misma, fuese enseñada en América con mentalidad cultural alemana. Ese era para Quesada el verdadero canje de profesores y no el planificado con la Universidad de París que solo servía para el intercambio de conferencistas destinado a un público extrauniversitario. Así, destacaría lo inconveniente de traer "conferencistas sueltos que hablen de generalidades y

\footnotetext{
${ }^{2}$ Las iniciativas de articulación de intercambio con Estados Unidos tuvieron escaso eco en los medios académicos locales, situación que probablemente reflejase también una percepción difundida entre sectores de las élites académicas que percibían en las propuestas culturales norteamericanas un medio para asegurar su hegemonía continental.

3 "Consejo Superior. Ordenanza sobre Intercambio de Profesores Universitarios, Septiembre 16 de 1912", Revista de la Universidad de Buenos Aires. Tomo XVIII. 1912. 299 y “Consejo Superior. Ordenanza Nº 86 de Intercambio permanente de Profesores con Francia", Revista de la Universidad de Buenos Aires, Tomo XXVIII. 1914. 137-138.

4 “Consejo Superior. Sesión de 1 de agosto de 1911", Revista de la Universidad de Buenos Aires, Tomo XV. 1911. 374-377.
}

Anuario de la Escuela de Historia Virtual - Año 10 - Nº 16 - 2019: pp. 25-50. ISSN: 1853-7049 
30 I Intercambio académico y disputas internacionales...

que recluten su público entre las gentes habituadas a teatros o salas de otro género". ${ }^{5}$ Afirmaba así que era fundamental lograr el intercambio de profesores regulares, ya que era la única manera en que el mismo pudiese tener un real impacto sobre la vida universitaria. A pesar de sus argumentos, el modelo francés fue en esta fase más exitoso. Los universitarios argentinos reconocieron el alto valor de las iniciativas francesas en el marco de una suerte de fraternidad intelectual de naturaleza latina.

Finalmente, en este contexto, deben anotarse las iniciativas impulsadas desde el mundo universitario español. Como ya señalamos, a partir de 1909 el historiador y profesor de la Universidad de Oviedo, Rafael Altamira, llevó a cabo un largo viaje que incluyó la visita a diversas universidades hispanoamericanas. Este viaje, cuyos pormenores fueron analizados por Gustavo Prado (2008), tenía como propósito proponer el canje regular de profesores, alumnos y material bibliográfico. El desarrollo de este proyecto también fue concebido a partir de la competencia con otros países, en particular con Estados Unidos.

\section{El impacto de la Primera Guerra}

Los proyectos e iniciativas se suspendieron a partir del inicio de la Primera Guerra Mundial. El Ministerio de Instrucción Pública de Francia postergó la iniciación del intercambio y la UBA suspendió la concesión de las becas para perfeccionamiento en el exterior. Si bien el tema pasó a un segundo plano, la cuestión académica y científica comenzó a ser cruzada -con una intensidad inédita- por consideraciones políticas y nacionales. El gobierno argentino mantuvo una actitud neutral durante la guerra, pero el mundo académico estuvo fuertemente afectado por el inicio y desarrollo de la contienda y las polémicas fueron muy intensas (García y Podgorny, 2000). Las controversias, en consonancia con tendencias más generales en la comunidad científica global, mostraban cómo el ámbito académico se fragmentaba frente a circunstancias de índole política.

La cuestión de los vínculos académicos externos ya no pudo ser tratada desde el inicio de la Gran Guerra sobre la base de consideraciones predominantemente científicas revelando esta circunstancia el impacto, en la Argentina, de la explosión nacionalista que sacudió a Europa al iniciarse la Guerra. Uno de los testimonios más interesantes de la manera en que la contienda afectó a la forma de observar las relaciones académicas con el exterior es la de un, por entonces, prestigioso médico que había estudiado en la Universidad de Friburgo, Josué Beruti (1920), quien publicó, en 1920, un texto bajo el título: “Beligerancia Científica. La Medicina Alemana”. Beruti denunciaba una campaña de desprestigio en la Argentina contra todo lo que tenía origen intelectual germano, la que atribuía a fuentes belgas y francesas. Simultáneamente, realizaba una ferviente

\footnotetext{
5 “Facultad de Filosofía y Letras. Sesión de 5 de Junio de 1911", Revista de la Universidad de Buenos Aires, Tomo XV. 1911. 399-404.
}

Anuario de la Escuela de Historia Virtual - Año 10 - N 16 - 2019: pp. 25-50. ISSN: 1853-7049 
defensa del carácter internacional del conocimiento científico. Afirmaba así que "nuestra cultura científica debe ser internacional", defendía el cosmopolitismo en el aprendizaje y sostenía que los logros científicos eran, necesariamente, el producto del contacto de civilizaciones diferentes. El texto conformaba un manifiesto en defensa de la construcción de un conocimiento no limitado por exclusivismos de naturaleza nacionalista (Reggiani, 2004). En este sentido, cabe destacar que la tensión entre grupos profranceses y progermanos fue particularmente intensa en el mundo académico porteño, pero también es preciso señalar que fue contrarrestada por figuras como la mencionada -en este caso un personaje identificado claramente con la academia alemanaque, de manera vehemente, defendieron el carácter abierto y cosmopolita de la ciencia y que intentaron limitar el impacto de las controversias políticas en el ámbito académico.

Más allá de esto, lo que puede advertirse es que, después de la Gran Guerra, el debate sobre el intercambio comenzó a transcurrir por carriles diferentes a los que había transitado hasta entonces. Los universitarios porteños siguieron mostrando escaso entusiasmo por las ofertas norteamericanas $y$, en un primer plano, privilegiaron los vínculos con estados latinoamericanos. Pero el espacio que la iniciativa francesa y alemana dejó libre fue ocupado durante estos años sobre todo por los científicos españoles.

\section{La reconstrucción de la posguerra: marcos institucionales}

Las iniciativas para reestructurar y reorganizar el intercambio aparecieron poco después de terminada la contienda. En este contexto fue fundamental la intervención de José Arce, figura central de la Facultad de Medicina y Rector de la UBA entre 1922 y 1926. La Facultad de Medicina cumplió, además, un papel de vanguardia en la reconstrucción del intercambio. En septiembre de 1920, el Consejo Directivo de la Facultad del que Arce era miembro- le solicitó que se ocupase de las gestiones con la Universidad de París. Fue el mismo Arce, ligado estrechamente al mundo académico francés, quien gestionó en el Consejo Superior el viaje de dos médicos de esa nacionalidad, Marcel Labbé y Emilio Brumpt y, más tarde, Pierre Abrami para que fueran a dar conferencias en Buenos Aires. Fue también él quien impulsó la inclusión en el Presupuesto Nacional de una partida para becas en el exterior. Cabe destacar que, a pesar de que Arce tenía sus principales contactos académicos con Francia, además insistió en la necesidad de dar espacio a los lazos con otros países, en particular con Alemania. El médico alemán Max Nonne brindó conferencias en este ámbito entre los años 1921 y 1922. Durante estos mismos años, la Facultad le encargó a su profesor, Vicente Dimitri, que gestionase el establecimiento del intercambio con las universidades alemanas. En julio

de 1922 Dimitri anunció en el Consejo Directivo que había obtenido facilidades ante el 
Ministerio de Salud Pública de Prusia para que los graduados de la Facultad pudiesen llevar a cabo residencias en los hospitales dependientes de ese organismo. ${ }^{6}$

De todas formas, lo fundamental aquí reside en señalar que durante la década del veinte el intercambio se reconstruyó sobre la base de mecanismos y modalidades distintas a las que habían caracterizado los proyectos de los primeros años del siglo. En principio, debemos tener en cuenta cómo la experiencia surgida de la guerra condicionó estas actividades. Como ya señalamos, el tema de la propaganda y la necesidad de ganar a la opinión pública de los países neutrales se convirtió en un imperativo central de la política de los estados que habían sido protagonistas del enfrentamiento. La tensión entre franceses y alemanes como es conocido continuó durante los años veinte y treinta y la política cultural y académica cobró aquí un peso mayor incluso al que había tenido hasta los inicios de la Guerra (Compagnon, 2014). Los informes y la correspondencia de los embajadores de Alemania y Francia en la Argentina durante los primeros años veinte exponen con claridad, en ese sentido, la importancia que otorgaban a las relaciones universitarias como una manera de ganar para su causa no solo a las élites, sino también a gran parte de la opinión pública. La correspondencia muestra además con claridad el recelo con que los funcionarios de cada embajada observaban la actividad de los representantes de otros estados y también la acción de las comunidades extranjeras residentes en el país. Más allá de esto, era claro, como ha señalado Stefan Rinke (1996) para el caso alemán, que se imponía la idea de que la política cultural debía fortalecer sobre todo los lazos entre los pueblos más que entre los gobiernos, de lo que puede inferirse que la preocupación por el impacto masivo de las actividades de intercambio se convertía en un tema dominante. De este modo, se configuraba como un factor más dentro de las estrategias propagandísticas. En particular, Alemania resolvió concentrar allí parte de sus esfuerzos en términos de política exterior frente a las limitaciones que le fueron impuestas por los vencedores en distintas áreas. Pero sin duda, la iniciativa en términos de articulación entre diplomacia política y cultural correspondió, una vez más, a Francia. Si bien los antecedentes de los componentes culturales de la política exterior pueden encontrarse aquí ya en la temprana modernidad, sus raíces contemporáneas -como ya señalamos- deben buscarse a mediados del siglo XIX con la fundación de los institutos culturales franceses en el exterior, con la creación de la Alianza Francesa en 1883 y con la del Bureau des Écoles et des Oeuvres Françaises à l' Étranger en 1900 (Balous, 1970; de Raymond, 2014, pp. 201-211). En ambos casos pueden advertirse ciertas tensiones o diferencias entre los objetivos con que las autoridades universitarias y numerosos académicos argentinos pensaron el papel de las prácticas de intercambio y la forma en que estas fueron finalmente instrumentadas por diversos actores, entre ellos, diplomáticos y científicos europeos que teñían a menudo sus

\footnotetext{
6 "Facultad de Ciencias Médicas. Sesión del 25 de Julio de 1922". Revista de la Universidad de Buenos Aires. Tomo L. 1922. 619-638.
}

Anuario de la Escuela de Historia Virtual - Año 10 - Nº 16 - 2019: pp. 25-50. ISSN: 1853-7049 
actividades de un marcado tinte político en un contexto de fuertes tensiones internacionales.

Por otro lado, una característica fundamental que asumió el intercambio académico en los años veinte estuvo vinculada, sobre todo, con el peso que adquirieron un conjunto de asociaciones, de instituciones no estatales o relativamente independientes del estado. La sorda disputa que durante los años veinte enfrentó a los integrantes de los servicios de las embajadas francesa y alemana en Buenos Aires no se libró en forma directa desde las mismas sedes diplomáticas, sino que procuró llevarse entonces a cabo a través de instituciones de la sociedad civil.

En consecuencia, una pregunta central que debemos plantearnos aquí refiere a las razones por las cuales la dirección del intercambio fue cedida a estas organizaciones. Stefan Rinke (1996) ha explicado el peso decisivo de estas asociaciones intermediarias en el caso germano por la debilidad del estado alemán de posguerra expresada entre otros aspectos en sus limitaciones financieras. Pero la presencia de este tipo de organizaciones se advierte también en los casos francés, italiano, español y norteamericano. Es posible entonces que, en cambio, se debiera a una estrategia común consistente en tratar de desvincular públicamente estas iniciativas de política exterior de los funcionarios políticos y diplomáticos de cada uno de los países involucrados y, al mismo tiempo, articularlas con los miembros de las comunidades migratorias de cada uno de ellos y también con los científicos vinculados por razones diversas, ya fuese por haber realizado en cada uno de estos estados sus estudios o por simpatizar con su causa. Los diplomáticos, en particular franceses y alemanes, incluso, pensaban que de la aparente disociación pública entre las iniciativas del intercambio y las agencias diplomáticas dependía el éxito masivo de aquellas. En este contexto, puede advertirse que una sugerencia del Ministro de Guerra Francés para encargar las acciones culturales al Agregado Militar en Buenos Aires fue rechazada firmemente por el Ministro de Asuntos Extranjeros, que señaló lo inconveniente que era que un funcionario del estado asumiese ese papel.7 Contemporáneamente, y como respuesta a la solicitud de un Ministro Español, un funcionario del Servicio Exterior Alemán señalaría que, ante la escasez de recursos, la política cultural debía apoyarse en las instituciones de la sociedad civil interesadas en los vínculos con Alemania. ${ }^{8}$ Es así que el intercambio académico de los años veinte fue posible en la Argentina y en otros estados latinoamericanos gracias a la acción de una serie de instituciones mediadoras o intermediarias que fueron las que lo orientaron y que, además, claramente lo condicionaron. Estas instituciones fueron, principalmente, el Instituto de la Universidad de París en Buenos Aires, la Institución Cultural Española y la Institución Cultural Argentino-Germánica. Si bien las tres tuvie-

\footnotetext{
${ }^{7}$ M. Millerand, Président du Conseil et Ministre des Affaires Étrangeres a M. André Lefévre, Ministre de la Guerre, París, 23 Juillet, 1920. En Ministère des Affaires Étrangères. Documents Diplomatiques Françaises, 1920. Tomo II. París, Impremerie Nationale. 1999. 304.

${ }^{8}$ Dr. Soehring, Relator y Consejero de Legación al Sr. Conde de Cañongo, Ministro de Estado- MadridBerlín, 11 de abril de 1923, en Politisches Archiv des Auswärtiges Amt, (PAAA) R. 60431.
}

Anuario de la Escuela de Historia Virtual - Año 10 - N 16 - 2019: pp. 25-50. ISSN: 1853-7049 
34 I Intercambio académico y disputas internacionales...

ron un papel importante en toda la década del veinte, las actividades de las dos primeras gozaron de un impacto público considerablemente mayor que el de la última. En un segundo plano, también debe mencionarse al Instituto de Cultura Itálica y a la Institución Cultural Argentino-Norteamericana.

Las tres instituciones mencionadas en primer término, de todas formas, tenían características distintas y también comprendían de manera diversa sus objetivos. La Institución Cultural Española fue el resultado de una iniciativa de la Asociación Patriótica Española, un organismo que nucleaba a personalidades destacadas de la comunidad española en Buenos Aires. Se fundó en 1912 y en sus orígenes fue dirigida por Avelino Gutiérrez, un profesor de la Facultad de Medicina nacido en Santander (Campomar y Zamora Bonilla, 2011; Campomar, 2009; Sepúlveda, 2007; López Sánchez, 2007; Formentín Ibáñez y Villegas Sanz, 1992). Sus miembros la consideraban como la expresión de una asociación de españoles que actuaba en la Argentina. Llevaba a cabo sus tareas en un contexto de clara reivindicación de la tradición peninsular propia de los tiempos del centenario y asumía en sus estatutos como uno de sus principales objetivos “... dar a conocer y difundir en la República Argentina las investigaciones y estudios científicos y literarios que se realicen en España". 9 Con ese propósito se estableció que la Institución sostendría una cátedra en la Universidad de Buenos Aires, la cual debía ser desempeñada por académicos españoles. Eran en definitiva los miembros de la colectividad de ese origen en la Argentina los que solventaban los costos de la cátedra. Un aspecto fundamental de su funcionamiento era que la decisión en torno a quiénes serían los invitados ya no quedaba en manos de la UBA, sino de la Junta para Ampliación de Estudios e Investigaciones Científicas (JAE), que dirigía Santiago Ramón y Cajal en Madrid. Este procedimiento era considerado el más adecuado para representar el verdadero potencial científico español y asegurar que fuesen los mejores académicos de ese origen los que tuviesen participación en el intercambio (Prado, 2007). La tarea de la Institución Cultural Española se inscribió entonces en el marco de una política más general concebida desde España y basada en la idea de la responsabilidad y tutela española sobre el nuevo mundo. Por otro lado, en alguna medida, estaba alejada del ideal celebrado por los académicos argentinos de principios de siglo, ya que, en este caso, la UBA perdía la capacidad de decidir quiénes participaban en el intercambio.

La Junta era una institución que tenía como objetivo contribuir al renacimiento científico de España. En principio, era independiente de las universidades peninsulares también moldeadas sobre un modelo profesionalista. La Institución Cultural Española, por su parte, con el apoyo de la UBA, financió regularmente el viaje de científicos designados por la Junta a lo largo de los años veinte. Muchos de ellos eran médicos, pero también filósofos como José Ortega y Gasset o matemáticos como Julio Rey Pastor.

\footnotetext{
9 “Orígenes de la Institución”, en Anales de la Institución Cultural Española, Tomo I. Años 1912-1920. 1947. $13-43$.
}

Anuario de la Escuela de Historia Virtual - Año 10 - Nº 16 - 2019: pp. 25-50. ISSN: 1853-7049 
Probablemente una de las contribuciones más importantes que llevó a cabo fue la vinculada con los estudios filológicos. Los viajes de Ramón Menéndez Pidal, Américo Castro y Amado Alonso, sobre todo, fueron fundamentales para el desarrollo de esa disciplina en la UBA.

La presencia de los españoles en el mundo académico argentino se afirmó entonces en los años de la guerra aprovechando el espacio que dejaron libre franceses y alemanes. Hasta entonces ni el mundo académico, ni el mundo científico español habían suscitado particular atención entre los universitarios argentinos. La principal ventaja de los españoles, en el marco de la guerra, estaba dada por la ausencia de sus principales competidores, pero también por la amplia disponibilidad de recursos de su comunidad en la Argentina. Fue sobre todo la iniciativa de esta última, más que la voluntad activa del gobierno español de reforzar sus vínculos con las repúblicas hispanoamericanas, la que impulsó en estos primeros años de la década de 1910 el intercambio académico con la península (Vélez, 2007; Sepúlveda, 2005). Por otro lado, debe notarse que la modalidad del intercambio articulada fundamentalmente a partir de la acción de la JAE y la Institución Cultural predominó frente a otras fórmulas que privilegiaban el vínculo de Universidad a Universidad como había impulsado la comunidad académica de Oviedo desde finales del siglo XIX. Pero, por otro lado, debe subrayarse también que Hispanoamérica constituyó siempre para las acciones desplegadas por la Junta un lugar secundario en lo que respecta a la política de intercambio (Prado, 2007).

A los factores mencionados que incentivaban el intercambio con España deben sumarse otros. Por supuesto, el idioma común, pero también el atractivo de algunas figuras capaces de interpelar a un público mucho más amplio que el que frecuentaba los recintos universitarios, como era el caso de José Ortega y Gasset. Las conferencias de este último constituyeron un evento público y social que transcendió el ámbito de los claustros. Pero, además, existían algunos núcleos de académicos locales que aspiraban especialmente a establecer lazos permanentes con investigadores e intelectuales españoles por razones eminentemente científicas. Uno de ellos estaba en la ya mencionada Facultad de Filosofía y Letras y procuraba organizar en la Argentina justamente los estudios de Filología. Cabe destacar aquí que la cuestión del lenguaje configuró a principios de siglo el espacio de un debate intenso. Las posiciones se polarizaron entonces entre quienes defendían, en este contexto, el uso del español puro y quienes aspiraban a construir un nuevo idioma en base a la mixtura del español y las expresiones idiomáticas generadas a partir de la inmigración. Otro de los ámbitos que debe mencionarse en este marco es el de las Ciencias Exactas, más específicamente el de Matemática. La posibilidad de contar con la colaboración de Julio Rey Pastor se reveló a los académicos de la Facultad de Ciencias Exactas - por entonces sobre todo una escuela de ingenieroscomo una oportunidad especial para desarrollar los estudios superiores y científicos en Matemática. Por último, por su formación y trayectorias, muchos de los académicos españoles podían convertirse en eficaces intermediarios entre el mundo académico argentino y otros sistemas universitarios europeos, particularmente, con el alemán. 
36 I Intercambio académico y disputas internacionales...

El Instituto de la Universidad de París en Buenos Aires cumplió también durante los años veinte un papel fundamental. En alguna medida era la expresión de la continuidad de una política de estado hacia Latinoamérica, que los gobiernos franceses venían siguiendo desde antes del inicio de la Gran Guerra, entre otras medidas, con la creación del Comité France-Amérique y de la Agrupación de las Universidades y Grandes Escuelas de Francia para las relaciones con América Latina (Matthieu, 1990). Poco antes de su inauguración, las autoridades francesas señalaban que el Instituto cumpliría un papel central y que era en las dimensiones de la vida intelectual donde la influencia de su país se podría hacer sentir en sus mejores términos. Era, además, el ámbito privilegiado para competir con los alemanes. En este sentido, se señalaba también el optimismo por el efecto positivo que podrían ejercer los hombres de ciencia y académicos franceses. ${ }^{10}$ Hebe Pelosi (1999) ha señalado que el Instituto logró traer a la Argentina como conferencistas a 62 académicos franceses entre 1921 y 1939. El Instituto recibiría una subvención del gobierno francés y otra del argentino, a través de la Universidad, y sus autoridades serían designadas por funcionarios de ambos gobiernos. Los conferencistas pertenecían a diferentes disciplinas, pero la Medicina y las disciplinas vinculadas con las Humanidades resultaron privilegiadas en este intercambio.

La iniciativa de creación del Instituto la tomó un grupo de académicos e intelectuales ligados, en su mayoría, a la UBA. En una reunión celebrada en septiembre de 1921 manifestaron su deseo de que el gobierno francés organizase en Buenos Aires un centro similar a los institutos culturales franceses que funcionaban en diversas capitales europeas. Al mismo tiempo, propiciaron la creación en París de un Instituto Cultural Argentino. La creación del organismo era percibida como la puesta en vigor de la antigua ordenanza de 1913 desactivada a raíz del inicio de la guerra.

Bajo la iniciativa de José Arce, en ese entonces Rector de la UBA, el Instituto se inauguró formalmente con un solemne acto en el Colegio Nacional de Buenos Aires (CNBA) con la presencia del Ministro francés en Buenos Aires, R. Clausse. En la organización, creación y comisión directiva participaron figuras relevantes del mundo académico tanto porteño como francés, en particular del ámbito de las humanidades y de los estudios relacionados con Hispanoamérica: Adolfo Bioy, Carlos Ibarguren y Diego Luis Molinari se destacaban entre las figuras vinculadas con la UBA. Georg Dumas y Ernest Martinenche tendrían un papel destacado entre los franceses. A lo largo de la década del 20 el Instituto mantuvo un funcionamiento regular amparado también en la simpatía que la iniciativa había concitado, entre otras figuras, en el mismo Presidente de la Nación, Marcelo T. de Alvear.

Es menos lo que se conoce sobre la Institución Cultural Argentino-Germánica. Fue fundada en un contexto signado por el boicot internacional a los académicos alemanes, que se prolongó hasta mediados de la década de 1920. En su fundación participó un

10 “Le Ministre de Guerre et des Pensions a M. Le Président du Conseil, Ministre des Affaires Étrangers, 21 Juin 1922, en Archives des Ministére des Affaires Étrangers (AMAE) (La Courneuve), Services des Oeuvres Françaises a l'Étrangers $N^{\circ} 45$, Serie O Carton XXVII, Dossier 1.

Anuario de la Escuela de Historia Virtual - Año 10 - N 16 - 2019: pp. 25-50. ISSN: 1853-7049 
grupo muy amplio y heterogéneo de académicos, políticos y miembros de la comunidad alemana en la Argentina. Entre ellos, se encontraban varios ex ministros, algunos de ellos caracterizados en el espacio público como germanófilos, académicos destacados y conocidos también por sus simpatías hacia Alemania, funcionarios del área cultural y de prensa de la Embajada y artistas como Fernando Fader. Un papel decisivo desempeñó en ella sobre todo un grupo de médicos. De las tres instituciones estudiadas aquí fue posiblemente la más débil por las limitaciones de sus apoyos internos y porque no fue reconocida desde un principio como una institución propia por parte de los funcionarios diplomáticos alemanes ni por los miembros de la colectividad de ese origen en la Argentina, pero también por aspectos relativos a las propias características del sistema universitario alemán caracterizado por su fuerte descentralización (Goebel, 2009). También fue la que experimentó los mayores debates internos. Uno de ellos, particularmente importante, fue el que se suscitó en su comisión directiva ante la posibilidad del viaje de Albert Einstein a la Argentina, realizado finalmente en 1925 gracias al aporte de un conjunto variado y diverso de instituciones. Un grupo de miembros de la comisión directiva propuso que la Institución le otorgase una distinción y otro, integrado por miembros de la comunidad alemana, rechazó la propuesta objetando entre otras cosas su actitud pacifista y "hostil a Alemania" durante la Gran Guerra y su condición de auténtico alemán, señalando que había optado por la nacionalidad suiza. La defensa de la figura de Einstein fue asumida entonces por el ex Decano de la Facultad de Filosofía y Letras, el filósofo Alejandro Korn, quien señaló que la institución debía respetar sus objetivos académicos y científicos sin involucrar a las cuestiones políticas en su seno. ${ }^{11}$ Luego del episodio, los miembros más prominentes de la comunidad alemana que habían formulado las objeciones se retiraron de la institución.

La Institución Cultural Argentino-Germánica, en sus primeros tiempos, fue presidida por el abogado y profesor en la Facultad de Derecho Ricardo Seeber, quien fue secundado por dos prestigiosos médicos formados parcialmente en Alemania, el ya mencionado Josué Beruti y Gregorio Aráoz Alfaro. Estos últimos cumplieron un papel destacado en las actividades de la institución. Por gestiones realizadas durante el Rectorado de Arce, también la Institución Cultural Argentino-Germánica obtuvo fondos de la Universidad para su funcionamiento junto a otros recursos provenientes del estado alemán y de la colectividad alemana. En sus orígenes fue, probablemente, la que procuró mantener el carácter más genuinamente científico, en la medida en que trató de mantenerse independiente de la embajada y la comunidad alemana local, lo que logró solo parcialmente. Por otra parte, promovió la visita de un grupo importante de eruditos, aunque en menor número que las instituciones mencionadas anteriormente. Su funcionamiento fue afectado por el carácter más descentralizado del sistema académico

\footnotetext{
${ }^{11}$ La descripción del debate fue realizada por un funcionario del área cultural de la embajada, Albert Haas, “Aufzeichnung. 4. 10.1922.", en PAAA, Akten 64677.
}

Anuario de la Escuela de Historia Virtual - Año 10 - Nº 16 - 2019: pp. 25-50. ISSN: 1853-7049 
38 I Intercambio académico y disputas internacionales...

germano y por la falta de articulación y superposición de funciones entre organismos diplomáticos, universidades e instituciones científicas autónomas alemanas. Los problemas financieros y las dificultades para encontrar profesores que pudiesen llevar a cabo sus exposiciones en español fue otro aspecto que conspiró contra sus actividades.

\section{Particularidades y modalidades del intercambio en los veinte: Facultades y disciplinas}

Examinadas globalmente, las actividades académicas llevadas a cabo en los años veinte presentan algunos rasgos particulares. El primer aspecto llamativo es el predominio entre los visitantes de médicos, por un lado, y de expertos en las disciplinas humanísticas, por otro. En términos de nacionalidades franceses y españoles se encontraban a la vanguardia, si se analiza la cuestión simplemente en función del número de invitados. Alemanes e italianos, y sobre todo norteamericanos, quedaban claramente relegados en un segundo lugar.

Las facultades de Ciencias Médicas y Filosofía y Letras fueron los escenarios principales del intercambio, lo que, en principio, puede explicarse por el mayor grado de internacionalización de sus disciplinas. En el caso de Medicina, como ya señalamos, el papel de José Arce fue central. Otras figuras de esa misma Facultad cumplieron un rol destacado en el intercambio como Avelino Gutiérrez, que además de ser un profesor y directivo activamente comprometido con la vida del organismo, era Presidente de la Institución Cultural Española. Por otra parte, dos de los principales impulsores de la Institución Cultural Argentino-Germana, Gregorio Aráoz Alfaro y Josué Beruti cumplirían un papel destacado en la misma Facultad.

Las autoridades de la Facultad de Filosofía y Letras, por su parte, siempre subrayaron la relevancia que tenían las instituciones culturales vinculadas con el intercambio en las actividades de la institución. Particularmente estrecha era, en este caso también, la relación con españoles y franceses. En agosto de 1922, el Decano se refirió a la importante cooperación que prestaba la Institución Cultural Española subrayando la influencia que tenía el vínculo establecido gracias a ella con figuras como Ortega y Gasset o Menéndez Pidal. ${ }^{12}$ En relación con el último, las autoridades de la Facultad insistieron en destacar su papel decisivo en el desarrollo de los estudios filológicos. Pero también ocuparon un lugar destacado aquí los franceses. Ernest Martinenche, anteriormente mencionado, quien fue además una figura central en el desarrollo de las políticas de cooperación intelectual entre Francia y América Latina, dictó durante varios años cursos sobre literatura española. Filosofía y Letras había sido definida inicialmente como una Facultad científica en un entorno universitario signado por el predominio de unidades académicas orientadas a la formación de profesionales liberales. Por otro lado,

\footnotetext{
12 “Actas de la Facultad de Filosofía y Letras, 2 de agosto de 1922", Revista de la Universidad de Buenos Aires, Tomo L. 1922. 1137-1139.
}

Anuario de la Escuela de Historia Virtual - Año 10 - N 16 - 2019: pp. 25-50. ISSN: 1853-7049 
una característica que llama la atención era la familiaridad de los académicos de la Facultad con la obra de gran parte de los intelectuales franceses que venían invitados para dictar conferencias. Era clara esta situación en los casos, por ejemplo, de Celestino Bouglé o de Albert Mathiez. ${ }^{13}$ La presencia de eruditos de esa nacionalidad tuvo en este caso una relevancia especial para el desarrollo de los estudios de Epistemología o Historia de la Ciencia. ${ }^{14}$

La otra Facultad que ocupó un papel destacado en el intercambio, en alguna medida también por la existencia de importantes figuras en su interior interesadas por el desarrollo científico, fue la de Ciencias Exactas. Aquí, probablemente, el papel central lo cumplieron los españoles. El rol de Julio Rey Pastor en el desarrollo de los estudios superiores de Matemática en la Argentina fue central. Rey Pastor arribó a la Argentina en el marco de las actividades de intercambio impulsadas por la Institución Cultural Española por primera vez en 1917, pero, posteriormente, a partir de contratos especiales y, luego, gracias a su designación como profesor ordinario, terminó radicándose parcialmente en la Argentina. En otras facultades, en cambio, el impacto medido por el número de conferencistas fue mucho menor, mostrando un escaso interés por este tipo de actividades. Fue el caso, sobre todo, de las Facultades de Agronomía y Veterinaria y de Ciencias Económicas y, en alguna medida, también de Derecho.

\section{Tensiones políticas: El intercambio como espacio de confrontación y diálogo}

Como hemos destacado anteriormente, es imposible comprender la evolución de las políticas de intercambio durante los años veinte sin tener presente la articulación de estas con la conflictiva situación internacional. Como hemos señalado en otros pasajes de este trabajo, los integrantes de los servicios diplomáticos, en particular de Francia y Alemania, asumieron la propaganda cultural como un elemento central en sus intentos de ganar para su causa a las élites de terceros países. Estos objetivos podían también conquistarse utilizando otros instrumentos: la difusión a través de la prensa, el respaldo activo a diferente tipo de iniciativas comerciales o la instalación de subsidiarias de sus empresas.

La politización de los ámbitos académicos estuvo también fuertemente condicionada por el modo en que, a menudo, los principales diarios reflejaban las conclusiones o los resultados de las conferencias en las que, subrayaban, especialmente, aquellas dimensiones discursivas más vinculadas especialmente con las disputas internacionales

Es importante tener presente, una vez más, que las propuestas de cooperación académica, ya fuese a través de conferencias o mediante la articulación y construcción de lazos científicos, estuvieron teñidas de consideraciones de tipo político desde los 20. Estas fueron particularmente explícitas en los casos francés y español, las iniciativas

\footnotetext{
${ }^{13}$ Emilio Ravignani: "Presentación de M. Mathiez en la Facultad de Filosofía y Letras", Archivos de la Universidad de Buenos Aires. Tomo IV.1929. 702-704

14 “Conferencias de M. Langevin”, Archivos de la Universidad de Buenos Aires. Tomo II. 1927. 359-362.
}

Anuario de la Escuela de Historia Virtual - Año 10 - N 16 - 2019: pp. 25-50. ISSN: 1853-7049 
40 | Intercambio académico y disputas internacionales...

que mayor repercusión tenían en los medios de prensa locales. En ambos casos, la idea de consolidar una identidad, ya fuese hispanoamericana o eurolatina, aparecía como el contrapeso necesario a la expansión sajona y, particularmente, al avance norteamericano. La nacionalización del discurso científico fue una variable que tiñó conferencias e intervenciones de académicos franceses y españoles, pero que también se reflejó en los discursos con los que los científicos argentinos los recibían. Es evidente que los modos o expectativas con que las autoridades académicas locales esperaban a los profesores extranjeros eran diferentes según su origen y nacionalidad. Así, a pesar del difícilmente admitido consenso a favor de la neutralidad, las ventajas de las relaciones culturales con los distintos países no eran percibidas ni presentadas en términos equivalentes o similares.

Probablemente, donde la cuestión se advierte con mayor claridad es en el trato y relación con los franceses, que eran recibidos en los ámbitos académicos argentinos con muestras de reconocimiento y con declaraciones que subrayaban la existencia de una afinidad intelectual cimentada en una identidad de carácter latino. En particular, en el ámbito de las disciplinas humanísticas puede notarse, como ya destacamos, además la familiaridad de las autoridades de la Facultad de Filosofía y Letras, particularmente de quien fuera su Decano durante los últimos años de esta década, Emilio Ravignani, con gran parte de la obra de los investigadores de origen francés.

En este sentido, cabe destacar que las demostraciones públicas de afinidad por parte de los académicos argentinos eran correspondidas por las palabras de los expositores franceses. En 1923, el historiador francés Raymond Ronze dictó una serie de conferencias en la Facultad de Filosofía y Letras. Si bien la mayor parte de sus intervenciones estuvo dedicada al examen de la obra de historiadores como Fustel de Coulanges, Thiers, Michelet o Tocqueville, dedicó la última de sus conferencias al examen de la situación internacional. Advirtió, en este contexto sobre los peligros de la expansión japonesa, tema que, según sus propias afirmaciones, lo llevaba necesariamente al análisis del panamericanismo. En este sentido, sostenía que tenía fuertes razones para creer en un panamericanismo latino, en el que "La República Argentina tiene un hermoso papel de dirección moral a desempeñar". ${ }^{15}$

La necesidad de acentuar los vínculos culturales entre Francia y la Argentina era, por otra parte, expuesta incesantemente por periódicos de gran tirada como La Nación. En noviembre de 1924 se publicó una nota del ex Presidente de Francia, Raymond Poincaré en la que advertía sobre la campaña emprendida en periódicos argentinos por parte de intereses alemanes para instalar una idea favorable a la causa de su país. La respuesta a esta campaña debía consistir en fortalecer los vínculos culturales entre los "latinos de Europa y de América". En este contexto cumplían un papel fundamental

15 “Instituto de la Universidad de París en Buenos Aires. Conferencias del Profesor Ronze. La disertación de ayer", La Prensa, 27 de septiembre de 1923.

Anuario de la Escuela de Historia Virtual - Año 10 - N 16 - 2019: pp. 25-50. ISSN: 1853-7049 
los viajes y el estudio mutuo. ${ }^{16}$ Por otra parte, en marzo de 1924 el mismo periódico publicó una nota del Rector de la Universidad de Valladolid, Calixto Valverde, en la que se destacaba la opinión favorable que primaba en España en torno a la política "hispanoamericana", subrayando que era el momento oportuno para dar impulso a las relaciones de pueblos hermanos unidos por los vínculos de la raza y el idioma. Cuestionaba entonces que el mejor camino fuese el del fortalecimiento de las relaciones económicas. Proponía, en cambio, basarse en la unión de los pueblos a través de "vínculos espirituales", por ser los más "íntimos y durables". ${ }^{17}$

El vínculo con los alemanes, en cambio, parece diferenciarse claramente de los casos francés y español. Si con franceses y españoles se subrayaba la afinidad cultural, con respecto a los alemanes se insistía en sus méritos científicos y en la pluralidad y amplitud de criterios del medio académico local. Esta circunstancia puede advertirse por ejemplo en la presentación que el entonces Decano de la Facultad de Filosofía y Letras, Emilio Ravignani, hizo de la figura de Otto Boelitz con motivo de la conferencia de este último en dicha institución en noviembre de 1927. Boelitz era una figura reconocida internacionalmente en el ámbito de la educación, ya que había desempeñado el cargo de Ministro de Instrucción Pública de Prusia. Ravignani sostuvo entonces en su presentación que la Facultad constituía “... un reflejo fiel de la modalidad de nuestra República, como argentinos, nos proponemos, al mismo tiempo que dar sentido a nuestra cultura, escuchar todas las voces de los países civilizados" ${ }^{18}$ Algo similar ocurrió con la visita del arqueólogo de la misma nacionalidad, Walter Lehmann, que dictó varias conferencias en la misma Facultad en agosto de 1929. Entonces Ravignani se limitó a señalar que se iniciaba "un ciclo de conferencias de vital interés no sólo para la cultura americana sino general". ${ }^{19}$

Con las otras comunidades los vínculos fueron más esporádicos. El Instituto de Cultura Itálica incidió en la visita de varios investigadores, entre los cuales, el más importante fue, probablemente, el de la educadora María Montessori. Quizás el vínculo teñido por los mayores recelos fue el establecido con los norteamericanos, cuyas visitas no fueron particularmente estimuladas por las autoridades de la Facultad de Filosofía y Letras. Coriolano Alberini sostendría también en su condición de Decano, al informar sobre una misión universitaria que le fuera encomendada en Estados Unidos, que "la cultura de Estados Unidos y la Argentina aún no tienen la vinculación que los intelectuales de ambos países anhelan establecer". ${ }^{20}$

\footnotetext{
16 "La evolución política de América. La idea de patria y la historia americana, la latinidad y el porvenir", La Nación, 29 de noviembre de 1924.

17 “Los estudios americanos en la Universidad de Valladolid”, La Nación, 23 de marzo de 1924.

18 "Presentación del doctor Otto Boelitz", Archivos de la Universidad de Buenos Aires. Tomo II. Buenos Aires. 1927. 649-652.

19 "El profesor alemán Dr. Lehmann dictó ayer su primera conferencia”, La Nación, 3 de agosto de 1929.

20 "La misión universitaria del profesor Alberini en los Estados Unidos", Archivos de la Universidad de Buenos Aires. Tomo II, 1927. 176-178.
}

Anuario de la Escuela de Historia Virtual - Año 10 - Nº 16 - 2019: pp. 25-50. ISSN: 1853-7049 
42 | Intercambio académico y disputas internacionales...

Pero también es preciso subrayar que, más allá de los recelos con que los agentes de los servicios diplomáticos, o incluso los miembros de las comunidades extranjeras, miraban las actividades de los académicos pertenecientes a naciones rivales, el intercambio se desarrolló en un ámbito de cordialidad. Junto a acciones que evidenciaban claramente la existencia de una fuerte competencia, había otras que reflejaban signos claros de respeto, consideración y colaboración, sobre todo, entre los integrantes locales de todas las instituciones intermediarias, incluso, entre las que representaban a alemanes y franceses. Una prueba de la aspiración a mantener signos de colaboración entre los miembros de las asociaciones puede advertirse, por ejemplo, en la presencia de miembros de algunas de ellas entre los fundadores o en el Consejo Directivo de las otras. Por ejemplo, Avelino Gutiérrez, Presidente de la Institución Cultural Española, José Arce, impulsor clave del Instituto de la Universidad de París y Nicolás Besio Moreno, primer Presidente del Instituto de Cultura Itálico, fueron invitados a participar del núcleo fundador de la Institución Cultural Argentino-Germánica.

\section{Algunas estrategias diferenciales}

En las estrategias llevadas a cabo por cada comunidad frente al sistema universitario también es posible observar diferencias significativas. Por ejemplo, aunque las visitas de los alemanes fueron, medidas en número o a través de su repercusión periodística, de menor impacto que las de franceses y españoles también es posible señalar que sus estrategias, sobre todo desde mediados de los años veinte, fueron cada vez más diversas y sus destinatarios más heterogéneos. Un aspecto relevante fue el impulso a las becas y facilidades para que graduados argentinos pudiesen llevar a cabo estudios en el exterior. En esto se diferenciaron de franceses y españoles que no se preocupaban particularmente por atraer a académicos argentinos hacia sus países y universidades, lo que generaba diversos tipos de quejas. A finales de 1927, la Institución Cultural Argentino-Germana anunció que la Fundación Alexander von Humboldt había ofrecido dos becas para que graduados de la Universidad de Buenos Aires pudiesen cursar dos semestres en una universidad alemana. La Institución Cultural complementaría las becas con una suma de dinero. ${ }^{21} \mathrm{Al}$ mismo tiempo, y como resultado de recomendaciones vertidas por la embajada, no solo se cursaron invitaciones para que personalidades de la vida universitaria local visitasen Alemania -incluso se organizó en 1928 una extensa excursión de profesionales y profesores a ese país con un plan de visitas a institutos médicos- sino que también se estableció una política de otorgamiento de distinciones, sobre todo a médicos, algunos por sus vínculos particulares con Alemania y otros por su papel decisivo en la conducción de las instituciones universitarias. Por lo general, estas distinciones eran concedidas por la Universidad de Hamburgo, que canaliza-

\footnotetext{
21 "Ordenanza aceptando las becas establecidas por la Institución Cultural Argentino-Germana", Archivos
} de la Universidad de Buenos Aires. Tomo I. 1925. 204-205.

Anuario de la Escuela de Historia Virtual - Año 10 - Nº 16 - 2019: pp. 25-50. ISSN: 1853-7049 
ba gran parte de los vínculos académicos con América Latina. Pero los actos de entrega tuvieron lugar en ceremonias formales llevadas a cabo en Buenos Aires. Fueron condecorados Gregorio Aráoz Alfaro, Mariano Castex, Josué Beruti y luego José Arce. En este último caso, fue clave la insistencia por parte de los miembros del servicio diplomático, que subrayaron la influencia de Arce en el mundo académico, pero también en la vida política porteña. El pedido fue cursado desde la embajada en mayo de 1926 señalando su condición de Rector, sus muestras de amistad hacia el embajador alemán y su estrecha relación con el Presidente. ${ }^{22}$ Esta estrategia inquietó a los franceses que, hacia finales de la década, procuraron contrarrestarla. George Dumas señaló, ante miembros del Servicio Diplomático Francés, en 1929, la necesidad de fortalecer esa práctica sugiriendo otorgar condecoraciones a Ricardo Levene, figura central de los estudios históricos y a José Oría, profesor de Literatura Francesa. ${ }^{23}$

La preocupación por asegurar cierta reciprocidad en las actividades de intercambio que caracterizó a los alemanes no fue entonces compartida globalmente por franceses y españoles. La falta de reciprocidad, en particular por parte de los universitarios franceses, fue, en este sentido, objeto de inquietud y de resquemores por parte de los académicos argentinos vinculados con el Instituto de la Universidad de París. Pero también la cuestión, como acabamos de señalar, fue advertida por los académicos franceses que tenían responsabilidad central en la gestión del intercambio. En la carta de Dumas, antes mencionada, se señalaba la conveniencia de efectuar una invitación a Emilio Ravignani para dar un curso en París sobre la influencia de la Revolución Francesa en la Revolución de Mayo.

Además, es preciso agregar que dentro de la estructura universitaria la intención de enviar becarios al exterior estuvo motorizada por algunas figuras en especial. Una de ellas fue Bernardo Houssay, futuro Premio Nobel de Medicina, quien insistió sobre el tema a lo largo de toda la década, comenzando tempranamente ya a finales de 1923. Los presupuestos universitarios incluyeron todavía en 1927 las becas de perfeccionamiento para estudios en el exterior. Estos fondos eran complementados a menudo por los provistos por las instituciones intermediarias, en particular, por el Instituto de Cultura Itálica, el Instituto de la Universidad de París y la Institución Cultural ArgentinoGermana. El caso más frecuente, como ya señalamos, nuevamente, fue, probablemente, el de esta última.

El impulso a la difusión de su propio idioma en el medio universitario fue también una estrategia que diferenció a alemanes de franceses. Los miembros del Servicio Exterior asentados en Buenos Aires y los directivos de la Institución Cultural comprendían que allí residía una de las principales trabas para extender su influencia cultural. Alemania no contaba por entonces con una institución que cumpliese las funciones de la

22 Véase la nota en $P A A A$, Abschrift VI-B4721.

${ }^{23}$ G. Dumas, Note pour M. Jean Marx au Sujet de mon Voyage en Argentine, novembre, 1929, Ministère des Affaires Étrangers, 21 juin 1922, en $A M A E$ (La Courneuve), Services des Oeuvres Françaises a 1' Étrangere, N 129.

Anuario de la Escuela de Historia Virtual - Año 10 - N 16 - 2019: pp. 25-50. ISSN: 1853-7049 
44 I Intercambio académico y disputas internacionales...

Alianza Francesa y, por consiguiente, debía impulsar por otros medios el desarrollo de la enseñanza de su idioma. Con ese propósito la Institución Cultural implementó cursos gratuitos de alemán en distintas facultades. Cabe destacar también, este sentido, que el conocimiento del francés parecía estar generalizado en el medio académico local. De hecho, dos de los principales invitados por la Institución Cultural, Albert Einstein y el Conde de Keyserling, brindaron sus conferencias, total en el primer caso y parcialmente, en el segundo, en francés.

Pero también los diplomáticos franceses procuraron fortalecer y extender aún más en el interior del mundo cultural y académico argentino la influencia de su idioma. La necesidad de impulsar el desarrollo de los Colegios franceses constituyó un tema de particular importancia para la diplomacia, que, además, siempre fue examinado en relación estrecha con el avance alemán en ese campo. Por otro lado, los franceses expusieron en más de una oportunidad su preocupación por el hecho de que el nacionalismo cultural en expansión en los ámbitos culturales y educativos argentinos perjudicaba la difusión de su lengua. ${ }^{24}$

\section{El impacto del intercambio en la vida académica: algunas hipótesis}

Uno de los problemas más agudos que plantea el estudio del intercambio académico refiere a su impacto en las actividades de docencia e investigación llevadas a cabo en el seno de la Universidad. En realidad, la gran mayoría de los invitados se limitó al dictado de una serie de conferencias dirigidas al público en general. La llegada de los visitantes extranjeros coincidió con el impulso a la política de extensión que las Universidades desarrollaron con posterioridad al movimiento de la Reforma de 1918. En el caso de la UBA, los ciclos de conferencias constituyeron una parte esencial de esta política de extensión que procuraba articular relaciones entre el ámbito universitario y el mundo cultural y social porteño. Novedades sobre política, salud, o literatura circulaban a través de este mundo de conferencistas (Bruno, 2014). Con esta orientación de las actividades de intercambio se cumplía uno de los presagios anunciados por Ernesto Quesada que, como ya destacamos, había cuestionado a principios de siglo los acuerdos de intercambio de profesores con Francia cuando aseguraba que con ellos se fortalecía la práctica de convocar a académicos para que dictasen conferencias para un público similar al que frecuentaba los teatros.

En este sentido, es importante subrayar que, posiblemente, las iniciativas de intercambio hubiesen despertado un interés mucho más reducido si el mundo cultural porteño no hubiese gozado del profundo dinamismo que lo signó durante los años 20. En esta sociedad relativamente próspera las clases medias en ascenso reclamaban espacios nuevos de entretenimiento, ocio y sociabilidad. El afán por conocer las novedades en

${ }^{24}$ D. Roustan, Inspecteur de la Academie de Paris en mission a Buenos Aires de 10 mars au 26 de octobre 1924. Note sur les relations intelectuales de la France et de l'Argentine, AMAE (La Courneuve), Services des Oeuvres Françaises a l'Étranger, N 129.

Anuario de la Escuela de Historia Virtual - Año 10 - Nº 16 - 2019: pp. 25-50. ISSN: 1853-7049 
términos literarios o científicos impulsaba la asistencia a diverso tipo de eventos. Las políticas de extensión que la UBA impulsó con éxito a través sobre todo de la Facultad de Filosofía y Letras se integraron en este activo mundo cultural. El ámbito universitario se articuló entonces con las iniciativas de organizaciones netamente culturales como la Asociación Amigos del Arte o de naturaleza política como la Sociedad Luz, vinculada al Partido Socialista. En estos espacios interactuaron muchos de los académicos que llegaron como resultado de las políticas de intercambio que hallaron entonces un escenario amplio mucho más allá del específicamente universitario. Además, el público que encontraron era sumamente heterogéneo y, como se señaló en más de una oportunidad, estaba más identificado con el que concurría regularmente a los teatros que con el que frecuentaba los recintos universitarios. En este sentido, como ha señalado Paula Bruno (2014), el hecho de que algunos de los académicos que llegaron a partir de iniciativas tomadas por instituciones universitarias contasen con diversas fuentes de financiamiento también incidía en la obligación de participar en eventos de distinto tipo y no necesariamente universitarios. Esto puede advertirse en casos como el de Albert Einstein. En la financiación de su viaje participaron, además de la UBA, y la Institución Cultural Argentino-Germánica, organismos vinculados con la comunidad judía argentina (Gangui y Ortiz, 2014). Los eventos en los que participaban estos académicos gozaban, por lo general, de una amplia repercusión periodística y eran comentados profusamente en los principales diarios de la capital. En gran medida, aquí radicaba también el interés de los integrantes de los servicios diplomáticos por participar en estas actividades ya que servían a menudo, de manera muy eficiente, para la difusión y propaganda de la causa de sus países.

En consecuencia, la orientación que asumió el intercambio no podía sino presentar fuertes limitaciones en lo que se refiere a su impacto concreto en las actividades de docencia e investigación. Pero tampoco debiera generalizarse un juicio de esta naturaleza, ya que algunas de las iniciativas surgidas en este marco perduraron e incidieron de manera fundamental en el desarrollo de ciertas disciplinas. Uno de estos casos está vinculado con la investigación y la docencia en matemática. En este ámbito, como ya señalamos, el papel desempeñado por el científico español Julio Rey Pastor fue fundamental. Las autoridades de Exactas, como lo harían también las de Filosofía y Letras, y a diferencia de las de Medicina o Derecho, intentaron darle mayor inserción y continuidad a la actividad de algunos profesores visitantes. El entonces Decano de Exactas, y luego Rector de la Universidad, Enrique Butty, cumplió un papel central en los esfuerzos por insertar a Rey Pastor dentro de la Facultad.

Los acuerdos con Rey Pastor fueron objeto de discusión, como lo eran por lo general, los intentos de contratación de profesores extranjeros que derivaban en designaciones permanentes. También aquí, frente a los beneficios de la cooperación, algunos consejeros insistieron en la necesidad de no contratar profesores extranjeros para desempeñar tareas que podían llevar a cabo los locales. Su contratación constituyó un objeto de debate en la Facultad desde mediados de la década de 1920 y fue evidente, en el 
46 I Intercambio académico y disputas internacionales...

transcurso de la discusión, la ausencia en el país de un núcleo de especialistas en condiciones de implementar los estudios superiores en Matemática. Otro caso relevante de inserción permanente en estos años fue el de Amado Alonso, quien además constituyó probablemente el último de una serie de filólogos españoles que pasó por la UBA a lo largo de los años veinte. Los intentos de conformar un Instituto de Filología en el ámbito de la UBA databan de 1922. Ricardo Rojas, por entonces Decano, llevó a cabo una serie de gestiones con ese propósito con Ramón Menéndez Pidal. Los primeros directores del nuevo instituto fueron sugeridos por este y habían sido sus colaboradores: Américo Castro, Agustín Millares Carlo, Manuel Montoliu y, finalmente, Amado Alonso (Buchbinder, 1997).

Las incorporaciones al sistema universitario de Julio Rey Pastor y Amado Alonso fueron fundamentales en tanto permitieron constituir desde los veinte y los treinta núcleos de investigadores especialistas en sus disciplinas. Fueron casos excepcionales como también lo fue el del científico argentino Bernardo Houssay- en una Universidad fundamentalmente profesionalista. Pero, además, cumplieron un papel destacado como intermediarios, ya que impulsaron la visita de otros investigadores extranjeros con el argumento de la relevancia de su obra y la oportunidad de su convocatoria. Incluso, como puede advertirse en el caso del geómetra italiano Federico Enriques -que vino invitado por el Instituto vinculado a esa colectividad- fue el mismo Rey Pastor quien presentó sus conferencias -y probablemente sugirió su invitación- y señaló que la geometría italiana se encontraba en un grado mayor de avance que la francesa o la alemana.

\section{Reflexiones finales}

La vida académica de la Universidad de Buenos Aires durante los años veinte estuvo surcada, entre otros aspectos, por la presencia permanente de profesores y científicos extranjeros que llegaron en el marco de una política que procuraba acentuar el perfil científico de la institución. El intercambio fue articulado por instituciones intermedias de diversas características y fue también condicionado por la acción de los diplomáticos asentados en Buenos Aires.

El intercambio tuvo una presencia importante en la prensa periódica de la ciudad, pero su impacto en la vida científica y cultural fue mucho más limitado con excepciones como las que pueden advertirse en los casos de las facultades de Filosofía y Letras y Ciencias Exactas. En este sentido, debe destacarse también que la naturaleza profesionalista de la vida universitaria porteña puso límites estrictos a las posibilidades de articulación de este movimiento cultural en la vida específicamente académica.

Cabe subrayar así que el intercambio conformó un capítulo significativo no solo de la vida universitaria, sino, sobre todo, del mundo cultural porteño, en términos generales. Como anticipara Ernesto Quesada, los huéspedes extranjeros participaron en ciclos de conferencias dedicadas al público en general. Esta orientación era, de todos modos, 
no solo consistente con los rasgos dominantes del sistema universitario argentino, sino también funcional a los objetivos de los miembros de los servicios diplomáticos que procuraban impulsarlo con estas características. Los franceses comprendían estas experiencias en el contexto de una política de propaganda que procuraba hacer públicas sus interpretaciones del origen de la Gran Guerra y confrontar así con el creciente avance norteamericano y, sobre todo, alemán en América Latina. Debe recordarse entonces que la política cultural francesa hacia el exterior gozaba de un dinamismo y posiblemente de un impacto mayor que el de los alemanes. La organización del Groupement des Universités et Grandes Écoles de France pour les Relations avec L'Amérique Latine marca un punto de inflexión y la presencia entre sus principales directivos de Luis Liard, Vicerrector de la Universidad de París y de Paul Apell, Decano de la Facultad de Ciencias de la misma Universidad, revela también la importancia que los académicos franceses otorgaban a los vínculos con América Latina.

Los historiadores franceses Jacques Chonchol y Guy Martinière (1985) han argumentado que en Buenos Aires no se consolidaron misiones científicas de larga duración como en Brasil porque el medio intelectual argentino tenía un peso y una densidad mayor que el de aquel país. Creemos que este juicio refleja una perspectiva quizás exageradamente sólida y consistente del mundo intelectual de la capital argentina, que era muy dinámico desde el punto de vista de su movimiento público, pero en el fondo menos rico y complejo de lo que suponen esos mismos juicios. El problema fundamental desde nuestra perspectiva es la existencia en la Argentina de un campo universitario consolidado, pero con una orientación claramente profesionalista que dejaba un espacio limitado a la investigación científica. En Brasil no había un espacio universitario con una densidad similar y, en consecuencia, el margen que existía para construir instituciones nuevas con una orientación a definir era mayor.

Por otra parte, los alemanes mostraron dificultades evidentes para adaptarse al estilo público que adquirió el intercambio y el impacto de sus actividades fue menor que el de franceses y españoles con la excepción, posiblemente, de los casos de Einstein y Keyserling. Además, mostraron límites mucho más pronunciados a la hora de articular sus discursos con dimensiones más amplias, en particular políticas. En esto se advierte la distancia con los académicos franceses, que poseían una notable capacidad para unir el discurso académico con una lectura política y lograban así un mayor acercamiento al público que asistía a las conferencias.

Pero también deben tenerse en cuenta aquí otras razones vinculadas con particularidades culturales e idiomáticas. Es preciso tener presente las características del sistema universitario alemán concentrado en la práctica de la ciencia y también su descentralización que hacía particularmente compleja la construcción de vínculos hacia el exterior por la superposición de agencias y actores. Por supuesto, la mayor afinidad y simpatía existente en el mundo académico local hacia Francia y España limitaba también el impacto público de sus actividades. Además, los universitarios argentinos tenían menos familiaridad con sus trabajos científicos.

Anuario de la Escuela de Historia Virtual - Año 10 - N 16 - 2019: pp. 25-50. ISSN: 1853-7049 
48 I Intercambio académico y disputas internacionales...

A través de estas experiencias, los alemanes descubrieron los límites de sus políticas culturales. Intentaron contrarrestar estas debilidades con una estrategia que procuró estimular la reciprocidad a partir de la concesión de becas a estudiantes y a través del otorgamiento de distinciones honoríficas a académicos. La intención manifiesta de una parte de los universitarios argentinos de preservar la neutralidad favoreció sus actividades. Textos recientes como el de Oliver Compagnon (2014) han insistido acertadamente en subrayar la francofilia dominante entre las élites argentinas. Pero, si bien el mundo académico expresó esta misma orientación, también conformó un espacio de tensión entre francófilos y partidarios de la neutralidad que, al margen de sus simpatías por la causa alemana, la defendieron, en función de valores universalistas y plurales que -consideraban-debían primar en el mundo científico.

En definitiva, el intercambio constituye un espacio particularmente apropiado para observar cómo desde principios de siglo se puso a prueba la pluralidad ideológica y política del mundo universitario argentino y cómo las controversias políticas derivadas de problemas de política internacional afectaron a las prácticas académicas. En este mismo sentido, permite observar las tensiones que el conflicto internacional desatado por la Primera Guerra Mundial desencadenó en el mundo de las élites científicas y profesionales argentinas.

\section{Referencias bibliográficas:}

Balous, S. (1970). L'action culturelle de la France dans le monde. París: Presses Universitaires de France.

Beruti, J. (1920). Beligerancia científica. La medicina alemana. Buenos Aires: Talleres Gráficos Brauche y Eggeling.

Bruno, P. (2014). Presentación. En P. Bruno (Coord.). Visitas culturales en la Argentina 1898-1936 (pp. 9-21). Buenos Aires: Editorial Biblos.

Buchbinder, P. (1997). Historia de la Facultad de Filosofía y Letras. Buenos Aires: Eudeba.

Campomar, M. (2009). Ortega y Gasset en la curva histórica de la Institución Cultural Española. Madrid: Biblioteca Nueva y Fundación José Ortega y Gasset.

Campomar, M. y Zamora Bonilla, J. (2011). Avelino Gutiérrez (1864-1946). La ciencia y la cultura en las dos orillas. En M. García Sebastiani (Dir.). Patriotas entre naciones. Elites inmigrantes españolas en Argentina (pp. 231-271). Madrid: Editorial Complutense.

Carreras, S. (2006). Historias de una migración peculiar: vidas académicas entre Alemania y Argentina (1870-1930). En I. Wehr (Ed.). Un continente en movimiento. Migraciones en América Latina (pp. 325-338). Frankfurt del Main: Vervuert Verlag.

Carreras, S. (2009) (Coord.). Migrantes de origen alemán en Argentina, Dossier Temático, Iberoamericana, IX (33), 85-87.

Charle, Ch.; Schriewer J. y Wagner, P. (Eds.) (2006). Redes Intelectuales Transnacionales. Madrid: Pomares Corredor.

Chicote, G. y Goebel, B. (2011). Ideas viajeras y sus objetos: El intercambio científico entre Alemania y América Austral. Frankfurt del Main/Madrid: Iberoamericana-Vervuert.

Anuario de la Escuela de Historia Virtual - Año 10 - № 16 - 2019: pp. 25-50. ISSN: 1853-7049 
Chonchol, J. y Martinière, G. (1985). L'Amérique Latine et le latino-américanisme en France. París: L'Harmattan.

Compagnon, O. (2014). América Latina y la Gran Guerra. Buenos Aires: Crítica.

Gangui, A. y Ortiz, E. L. (2014). Albert Einstein en la Argentina: el impacto científico de su visita. En P. Bruno (coord.). Visitas Culturales en la Argentina, 1898-1936 (pp. 167189). Buenos Aires: Biblos.

Goebel, M. (2009). Decentring the German Spirit. The Weimar Republic's Cultural Relations with Latin America. Journal of Contemporary History, 44 (2), 221-245.

De la Hera Martínez, J. (2003). La política cultural de Alemania en España en el período de entreguerras. Madrid: CSIC.

Delgado Gómez Escalonilla, L. (1992). Imperio de papel. Acción cultural y política exterior durante el primer franquismo. Madrid: CSIC.

De Raymond, J. F. (2014). La Diplomatie Culturelle, spécificité française. En L. Vidat y D. Poton (Dirs.). Du Brasil a l'Atlantique. Essai pour une histoire des échanges culturelles internationaux. Mélanges offerts a Guy Martinière (pp. 25-57). Rennes: Presses Universitaires de Rennes.

Formentín Ibáñez, J. y Villegas Sanz, J. M. (1992). Relaciones Culturales entre España y América: La Junta para Ampliación de Estudios. Madrid: MAPFRE.

García, S. y Podgorny, I. (2000). El sabio tiene una patria. La Gran Guerra y la comunidad científica argentina. Ciencia Hoy, 55, 24-34.

López Sánchez, J. M. (2007). La Junta para Ampliación de Estudios y su proyección americanista: la Institución Cultural Española. Revista de Indias, LVII (239), 81-102.

Matthieu, G. (1990). Un Enjeu diplomatique: La politique culturelle de la France en Amérique du Sud Dans l'Entre deux guerres. Cahiers des Amériques latines, 9, 27-45.

Molinuevo, J. L. (Coord.) (1997). Ortega y la Argentina. Madrid: FCE.

Pelosi, H. (1999). Argentinos en Francia. Franceses en Argentina. Una biografía colectiva. Buenos Aires: Ciudad Argentina.

Posada, A. (1911). Relaciones Científicas con América. Madrid: Establecimiento Tipográfico de Fontanet.

Prado, G. H. (2008). Rafael Altamira en América (1909-1910). Historia e Historiografía del proyecto americanista de la Universidad de Oviedo. Madrid: CSIC.

Prado, G. H. (2007). La Universidad de Oviedo, Rafael Altamira y la JAE: controversias en torno a la gestión de las relaciones intelectuales hispano-americanas (1909-1911). Revista de Indias, LXVII (239), 33-58.

Pyenson, L. (1985). Cultural Imperialism and Exact Sciences. German Expansion Overseas. Nueva York: Peter Lang.

Quesada, E. (1916). El nuevo panamericanismo y el congreso científico de Washington. Buenos Aires: Talleres Gráficos del Ministerio de Agricultura de la Nación.

Rama, C. (1982). Historia de las relaciones culturales entre España y la América Latina. Madrid: FCE.

Reggiani, A. (2004). De rastacueros a expertos. Modernización, diplomacia y circuitos académicos transnacionales. En R. Salvatore (Comp.). Los lugares del saber. Contextos locales y redes transnacionales en la formación del conocimiento moderno (pp. 159-187). Buenos Aires: Beatriz Viterbo.

Rinke, S. (1996). 'Der letzte freie Kontinent': Deutsche Lateinamerikapolitik im Zeichen transnationaler Beziehungen, 1918-1933. Stuttgart: Verlag Hans-Dieter Heinz. 
50 I Intercambio académico y disputas internacionales...

Salvatore, R. (2004) (Comp.). Los lugares del saber. Contextos locales y redes transnacionales en la formación del conocimiento moderno. Buenos Aires: Beatriz Viterbo.

Salvatore, R. (2004a). Saber hemisférico y disonancias locales. Leo S. Rowe en Argentina, 1906-1919. En R. Salvatore (Comp.). Los lugares del saber. Contextos locales $y$ redes transnacionales en la formación del conocimiento moderno (pp. 327-365). Buenos Aires: Beatriz Viterbo.

Sepúlveda, I. (2007). La JAE en la política cultural de España hacia América, Revista de Indias, LVII (239), 59-80.

Sepúlveda, I. (1994). Comunidad cultural e Hispanoamericanismo, 1885-1936. Madrid: UNED.

Sepúlveda, I. (2005). El sueño de la madre patria. Hispanoamericanismo y Nacionalismo. Madrid: Marcial Pons.

Vélez, P. (2007). La historiografía americanista en España. Madrid/Frankfurt del Main: Iberoamericana Vervuert.

Wagner, P. (2006). Introducción a la Primera parte. En Ch. Charle; J. Schriewer y P. Wagner (Eds.). Redes Intelectuales Transnacionales. Madrid: Pomares Corredor.

Para citar este artículo:

Buchbinder, Pablo (2019). Intercambio académico y disputas internacionales: La Universidad de Buenos Aires en los años 20. Anuario de la Escuela de Historia Virtual, 16, 25-50. 